\title{
La guerra como administración estatal. La Guerra Civil colombiana de 1851
}

\author{
por \\ Juan Carlos Jurado Jurado \\ Universidad EAFIT, Medellín-Colombia
}

\begin{abstract}
La guerra es caos y destrucción pero ha significado la construcción de órdenes modernos como la nación Estado. En este artículo se trata la Guerra Civil colombiana de 1851 como experiencia administrativa para el Estado, pues le significó la planeación, coordinación y control de ingentes recursos para gobernar y construir su legitimidad política. Se tratan las acciones políticas como acciones administrativas, los costos de la guerra y la precariedad del Estado a partir del análisis de memorias, crónicas, correspondencia oficial y prensa.
\end{abstract}

PALABRAS ClAVES: guerra civil de 1851; administración; construcción de la nación.

\section{INTRODUCCIÓN}

Entre mayo y septiembre de 1851, tuvo lugar en la Nueva Granada una guerra civil en la que el partido Conservador se levantó en armas contra las reformas progresistas del Gobierno del liberal José Hilario López (18491853). Éste lideró una serie de políticas de modernización en ruptura con el persistente pasado colonial, denominadas en la historiografía colombiana como las «Reformas Liberales». Se trataba de poner el país a tono con las exigencias de la economía mundial, y de darle a la sociedad un carácter más democrático y laico, lo que suponía quebrantar los viejos sistemas de dominio social y cultural de la aristocracia colonial y de la Iglesia Católica. No obstante que la Guerra Civil de 1851 tuvo muy poca duración -132 días-, su impacto en la vida política nacional se ubica en todo el quiebre de mitad del siglo XIX. Dado que su contenido político e ideológico fueron las Reformas 
Liberales, adquiere un significado complejo y amplio referido a los procesos de construcción de la nación y el Estado, durante tal centuria ${ }^{1}$.

La Guerra Civil de 1851 fue la más corta del siglo XIX, y como tal duró entre el 1 mayo -con los levantamientos de los terratenientes y esclavistas conservadores Julio Arboleda y Manuel Ibáñez en las provincias del sur-occidente-, y el 10 de septiembre, con la derrota del general caleño Eusebio Borrero en la antigua provincia de Antioquia, en la localidad de Rionegro, iniciada el 1 de julio. Entre estos dos hechos se sucedieron dos levantamientos regionales más, los principales en las provincias de Mariquita y Neiva planeados para el 20 de julio, por el coronel y hacendado Mateo Viana, Francisco de Paula Diago y el general José Vargas Paris, así como los hermanos Francisco y Domingo Caicedo y sus peones y labriegos reclutados en sus haciendas. En el movimiento insurgente del centro Oriente los rebeldes también fueron importantes hacendados del hinterland dominado por la capital de la República, entre los que se destacó el popular terrateniente José María Ardila, dueño de la hacienda Corito en Facatativá, Pastor Ospina (hermano de Mariano Ospina Rodríguez, líder nacional de la oposición al Gobierno), quien se levantó en la localidad de Guasca, con gran influjo político en las localidades de Guatavita, Sopó y Gachetá donde reclutó tropas de campesinos y propietarios con las que armó guerrillas. Por último, Juan Nepomuceno Neira, político regional, afamado abogado y profesor de Derecho, representante ante el Congreso por la ciudad de Tunja.

La Guerra Civil de 1851 tuvo un alto componente regional, pues se estructuró a partir de un complejo conjunto de rebeliones regionales y locales, débilmente articuladas como movimiento nacional, a pesar de lograr construir unas justificaciones y unos objetivos unificados: Convención, Dios y Sistema Federal. Se trataba de ejércitos regionales, pequeños, mal organizados, poco armados, liderados principalmente por civiles inexpertos, que no pudieron superar su insularidad territorial, y de ahí su incapacidad para construir una típica guerra civil, abierta y generalizada. De esta forma la contienda expresó la fragmentación de las elites regionales, además por la carencia de una figura de peso nacional que lograra unificar efectivamente al movimiento rebelde y a todas las fuerzas del partido Conservador contra el Gobierno liberal, dividido desde las elecciones presidenciales de 1849. Por todo ello fue calificada por sus contemporáneos, como una «guerra de rebeliones», lo que implica

1 Sobre la Guerra de 1851 existen varios trabajos de diverso orden: Helguera, 5 (Bogotá, 1970): 53-63. Ortiz Mesa, 1985. Valencia Llano, 1998: 37-57; 2008. Uribe y López, 2006. González, 2006: 36-57. 
que tampoco se trató de una guerra «magna» como las de 1860 y la de Los Mil Días (1899-1902)2.

No obstante que la guerra está signada por la muerte, el caos y la destrucción, debido a que es una dramática manifestación de la violencia humana, por su carácter complejo, dialéctico y paradójico, también trae consigo la construcción de nuevos órdenes sociales y políticos. Las relaciones entre guerras y los procesos de formación de las naciones han ocupado un importante lugar en las ciencias sociales, y han definido una amplia gama de problemáticas referidas a la definición de identidades regionales, procesos de poblamiento, definición de territorios, fronteras y soberanías, instituciones de poder con sus expresiones de obediencia, lealtad y consenso, y la articulación de comunidades políticas modernas ${ }^{3}$. Un amplio abanico de investigadores de la historia social y de la sociología como Perry Anderson, Eric Hobsbawn, Charles Tilly, Benedict Anderson, Theda Skocpol y Norbert Elías, entre otros, ha destacado la profunda relación entre guerras civiles y los procesos de formación de los Estados nacionales a partir de la compleja y larga transición de la Edad Media a la sociedad moderna. Según estos autores, los mecanismos y procesos de hegemonía y monopolización de diversos recursos militares, sociales, políticos y culturales propios de un territorio, responden a la configuración de un órgano de poder centralizado y unificado denominado Estado nación ${ }^{4}$.

En este sentido, son muchos los aspectos y problemas para indagar que dan cuenta del significado de la contienda en cuanto a la construcción del orden nacional, lo que implica reconocer las motivaciones y determinantes políticos, económicos y sociales de la misma, los mecanismos militares, políticos e ideológicos de participación y movilización de los sectores populares, del clero y las elites, que fueron claves en la configuración de los partidos políticos y las regiones, procesos que fueron más nítidos en la coyuntura de mitad de siglo5.

Entre los múltiples temas de interés que suscita la Guerra Civil de 1851, y que constituye el objeto de este artículo, me interesa indagar la guerra civil como experiencia de administración pública. Se trata de analizar la forma como la contienda militar forzó al ente estatal a fungir como agente adminis-

\footnotetext{
2 El Neogranadino, 15 de agosto de 1851, año IV, n. ${ }^{\circ}$ 169, p. 267.

3 Uribe, 18 (Medellín, enero-junio de 2001): 9. Guerra, 2001: 85-102.

${ }^{4}$ Anderson, 1982. Hobsbawn, 2000. Tilly, 1992. Anderson, 2003. Skocpol, 1983. Elias, 5 (Medellín, 1998). Uribe y López, 2006: 30.

5 Algunos de estos aspectos los he tratado en: Jurado, 15 (Medellín, julio-diciembre de 2008): 43-88; y Jurado, 71 (Bogotá, enero-abril de 2011): 3-28.
} 
trativo y de poder burocrático, situación que no obstante la inestabilidad que le generaba, también le implicaba aprendizajes para la organización estatal en cuanto a la construcción de su legitimidad y su capacidad de hegemonía en el territorio nacional. En este sentido, es necesario tener presente que las acciones emprendidas por las oficinas gubernamentales y la burocracia estatal para responder a las urgencias de la guerra como la provisión y gestión de recursos de todo orden, el movimiento de tropas, la contratación de armas y aprovisionamiento de los ejércitos así como el espionaje y la circulación de informes y correspondencia e instrucciones de todo tipo, significaron la formación del Estado como ente centralizado de poder y de administración pública.

\section{Acciones POlíticAs eStATALES COMO ACCIONES ADMINISTRATIVAS}

Considerar la formación y consolidación del Estado como estructura de poder, en relación con su función administrativa en la vida nacional, ha sido sugerido con la legendaria frase de Bertrand de Jovenel, cuando declara: «En política, la acción es finalmente administración» ${ }^{6}$. Este es un camino para entender la manera como los organismos político administrativos pudieron, con el tiempo, llegar a ser considerados «patrias», debido a su capacidad para crear significados de filiación e identidad política ${ }^{7}$.

En este mismo sentido y en relación al largo proceso de formación del Estado nación en Europa occidental y las guerras, es imprescindible considerar el trabajo del historiador Charles Tilly, en el que afirma: «Un importante esfuerzo bélico producía por lo general una expansión permanente del aparato central del Estado» en cuanto al número de personal a tiempo completo, al alcance de sus instituciones, a las dimensiones del presupuesto e, incluso, a la extensión de su deuda ${ }^{8}$. En consonancia con ello, los registros históricos manifiestan relativas y puntuales ampliaciones del aparato estatal en medio de la Guerra Civil de 1851 con la contratación y dotación de armas para cuantiosos militares y tropas, principalmente los guardias nacionales y los civiles liberales integrantes de las Sociedades Democráticas, para desplazarlos a lo largo del territorio nacional; el acopio de vestuario, raciones de comida y medicinas, por parte de funcionarios del Estado con algunos particulares; la consecución de mulas, caballos y el pago de transporte de bastimentos y armas

\footnotetext{
6 Citado en Palacios, 1999: 201.

7 Anderson, 2003: 84.

8 Tilly, 1992: 140.
} 
con particulares; la ampliación de las tropas veteranas, cuyo pie de fuerza permitido en tiempos de paz fue de 1.500 soldados y que pudo ascender a 10.000 con las afujías de la contienda; la disposición y ampliación de oficinas, archivos, papelería, correos y, todo un esfuerzo contable y administrativo que garantizara la correcta circulación de trámites, órdenes, instrucciones y hombres a lo largo del territorio nacional. Otras funciones más específicas tuvieron que ver con los reclutamientos, los ascensos y las bajas del personal militar, el registro y castigo de los desertores, la administración de hospitales militares, la definición de los circuitos de espionaje, la coordinación de operaciones militares con las autoridades locales y su acción sinérgica con otras dependencias del Gobierno central, y funciones de posguerra como el tratamiento de las víctimas y las pensiones de sus familias y viudas, entre otros aspectos, como la administración de la justicia relativa a indultos, amnistías y retaliaciones.

Más allá de la guerra misma, se observa que cuando el aparato estatal tomaba medidas de diverso orden sobre su territorio y su población, como las Reformas Liberales, hacía posible que la política hiciera presencia a todo lo largo de la nación. Para tener una idea de cómo afectaba el poder estatal a lo más recóndito del mundo rural, debe recordarse, según el historiador Malcolm Deas, que el Estado llegaba por medio del aparato fiscal, y así el contribuyente -por medio del pago del diezmo o la tan debatida contribución directa y la descentralización de rentas (1850) - tenía la sensación de ser parte de una comunidad mayor; la manumisión de los esclavos, decidida por el Gobierno nacional, que tanto afectó la vida de los esclavos y los derechos de propiedad de los hacendados; la conformación de milicias y el reclutamiento de soldados, frente al que las comunidades y la oposición manifestaron su descontento y temor $^{9}$, y las delimitaciones administrativas regionales impregnadas de intereses políticos, como la división de la provincia de Antioquia, entre otras ${ }^{10}$. De igual manera, el Estado estableció relaciones directas con las personas por medio de la ley penal, en la que se hallaba «todo contenido político» del aparato estatal dirigido a las rutinas de la vida cotidiana personal; el recorte de los fueros de la reglamentación de la Iglesia, que tan profundos rencores suscitó entre los prelados y en las comunidades ultra católicas; las elecciones y la administración civil, cuyo juego de decisiones administrativas por parte de los burócratas afectaba innegablemente el curso de la vida diaria local, y aspectos tan disímiles e importantes como la educación, entre muchos otros ${ }^{11}$.

\footnotetext{
9 Jurado, LXIV/232 (Madrid, 2004): 673-696.

10 Jurado, 17 (Medellín, julio-diciembre de 2009): 121-158.

11 Deas, 1983: 149-173.
} 
Todo lo anterior revela que las tan debatidas reformas implementadas por el Gobierno de López fueron un importante escenario político para que el Estado tuviera presencia de forma efectiva en la vida de las personas a lo largo del territorio nacional y sus regiones, y suscitara entre los más humildes parroquianos el sentimiento de formar parte, más allá de su comunidad vital, de una comunidad política mayor, la nación ${ }^{12}$. Independientemente del grado de efectividad que tuvieran las reformas implementadas por el Gobierno liberal y sus acciones militares en medio de la guerra, es importante destacar que pudieron crear expectativas «organizativas» sobre el Estado como entidad de gestión y coacción que pretendía controlar su territorio y su población. Éste sigue siendo el mínimo de definición soberana de cualquier Estado moderno, desde los siglos XVI y XVII ${ }^{13}$.

En tal sentido y como lo indica el historiador Marco Palacios, las guerras civiles colombianas fueron «una escuela abierta de administración pública», debido a que forzaron su organización administrativa desde la necesidad de asumir la planeación de toda una logística, dado que «en breves lapsos de tiempo debían acopiarse y distribuirse enormes cantidades de recursos humanos, financieros, materiales y de armas» para atender las necesidades de las tropas y de asegurar la estabilidad del Gobierno ${ }^{14}$. Este complejo rol administrativo le dio al Estado una importante experiencia en su función de gobernar y controlar, así como la tan necesaria legitimidad, que se medía por la eficacia en la gestión de sus recursos y en el logro de los resultados.

Pese a la brevedad de la Guerra Civil de 1851, se puede afirmar que con el despliegue de su extendida, aunque precaria maquinaria administrativa por el territorio nacional, el Estado construye la nación, pero también se construye a sí mismo como órgano de poder burocrático y de acción política. Se trata en definitiva de una larga y compleja serie de funciones administrativas que en los documentos oficiales de la época se agruparon bajo el apelativo de «Ciencia de Gobierno» ${ }^{15}$ referida a la planeación, coordinación, organización, dirección y control de recursos y procedimientos económicos, militares y administrativos. De esta forma, los burócratas parecían referirse a las acciones

12 Benedict Anderson cita a Seton-Watson cuando dice: «Sólo puedo decir que una nación existe cuando un número considerable de miembros de una comunidad consideran formar parte de una nación, o se comportan como si así ocurriera». Aquí podríamos traducir «consideran» por «imaginan». Anderson, 2003: 23, nota 9.

13 Orozco, 2006: 103-104.

14 Palacios, 1999: 251-252.

15 Informe del Secretario de Estado del Despacho de la Nueva Granada al Congreso Constitucional de 1852. Secretaría de Guerra, escrito por Valerio Barriga, Bogotá, 1852, Biblioteca Nacional de Colombia (BNC), Fondo Pineda, p. 39. 
de gestión propiamente dichas y no al sustantivo que recoge el conjunto de oficinas estatales: la «Administración Pública». Todo lo cual comprometía el funcionamiento de la entidad estatal conformada por «funcionarios ejecutivos», íntimamente relacionados con el ordenamiento político interno y con la adopción de los métodos de administración pública más modernos de enton$\operatorname{ces}^{16}$. Por ello, se podría afirmar que toda acción administrativa fue finalmente una acción política, dirigida a crear y sostener un orden político relacionado con el gobierno del territorio y su población, ámbito interno, pero también externo, por ejemplo los Estados vecinos, como Ecuador, ante la posibilidad de una confrontación militar con el país vecino, debido al asilo que brindara a la expulsada Compañía de Jesús de la Nueva Granada. Al respecto, valga un ejemplo acerca de las decisiones que fue necesario tomar acerca de las fortificaciones militares, según texto de la Secretaría de Estado:

Confiada al Poder Ejecutivo por la Constitución, i por todos los sanos principios de la ciencia de Gobierno, la defensa de la República contra los enemigos esteriores e interiores, a él toca juzgar la conveniencia de conservar o no las fortalezas; i facultarlo para que resuelva sobre este punto, no sería sino autorizar para que hiciera uso de sus atribuciones naturales. El podría, con el conocimiento de las necesidades nacionales o locales, utilizar a favor de la Nación aquellos edificios que, a lo más, sólo sirven actualmente para ocasionar gastos. I por si esta idea fuese acojida por los representantes del pueblo, yo me atrevo a presentar un proyecto de lei $[\ldots]^{17}$.

La cita hace visible el problema de despliegue del Estado que construye la nación como organismo efectivo de gobierno en su espacio territorial natural, lo que significaba la eliminación de contra-poderes internos como la insurgencia armada, o paralelos, consistente en la amenaza de un Estado vecino como Ecuador, para establecer su soberanía plena e incuestionable; lo cual evidencia que la competencia interna de poder que el Estado neogranadino enfrentaba, hacía más compleja la conquista de legitimidad y capacidad para desenvolverse en el ámbito internacional.

En medio de la Guerra Civil de 1851, las diferentes dependencias del Estado, y particularmente la Secretaría de Guerra, debieron proveer a sus cuerpos armados de los recursos necesarios con el máximo de economías posibles, por

${ }^{16}$ Los «funcionarios ejecutivos» designan la burocracia estatal que obtiene recursos, y constituye y representa al Estado como »organización administrativa y coactiva». Skocpol, 1983: 65-66.

17 Informe del Secretario de Estado del Despacho de Guerra de la Nueva Granada al Congreso Constitucional de 1852. Secretaría de Guerra, escrito por Valerio Barriga, Bogotá, 1852, BNC, Fondo Pineda, p. 39. 
lo que se vio forzada a responder con una sorprendente capacidad administrativa y de gestión, lo que contribuyó al funcionamiento del Estado como órgano centralizado de poder capaz de racionalizar los recursos nacionales y ejercer el monopolio de la violencia. Ello implicaba la elaboración de diligentes y enormes contratos con particulares, que pudieron hacer jugosos negocios como proveedores del Estado, lo cual se concluye del mencionado informe de la Secretaría de Guerra al Congreso de 1852, donde se registró la gestión de dicha dependencia durante el año previo. El informe refiere los contratos con proveedores nacionales y extranjeros para dotar a los cuerpos de veteranos y a los Guardias Nacionales de los más diversos implementos para su desempeño: vestuario y uniformes, armamento, correajes, el arrendamiento y adecuación de edificios y, por supuesto las raciones de comida, la organización y paga de hospitales y medicinas, y el transporte de personal, correos y víveres. Para dar una idea de los cuantiosos gastos que esta amplia variedad de implementos suponía, el secretario de Guerra mencionaba que en sólo las provincias de Bogotá, Popayán, Córdova y Medellín, la cifra pagada por vestuario, a diciembre 31 de 1851, ascendía a casi $\$ 552.000$ pesos, lo que correspondía a un cuarto del gasto público anual, que durante los años de la década de 1850 pudo ascender a dos millones de pesos ${ }^{18}$. Mientras que las armas, fornituras, medicinas y otras tantas dotaciones en otras provincias ascendieron a un costo de $\$ 353.000$ pesos. El documento refiere que en semejante situación tan crítica se había comprado a un comerciante extranjero 2.000 fusiles, 300 carabinas, 300 rifles de percusión y 400 sables. Como clara muestra de que estas adquisiciones significaban excepcionales y jugosos negocios para algunos intermediarios y comerciantes, decía el funcionario:

El no haber llegado a tiempo los vestuarios, ha hecho necesario hacer contratas para proveer del cuartel a los cuerpos veteranos, i como no se había calculado, sino el necesario para el píe de fuerza en tiempo de paz [o sea la cifra de 1.500], ha sido indispensable contratar para las guardias nacionales que tan importantes servicios han prestado a la República. Las contratas se han celebrado con la urgencia que lo exigía por que no podía ser de otra manera, i aunque el interés privado, procurase como siempre sacar en su favor todas las ventajas posibles, puede asegurarse que jamás contratas de esta clase se han hecho en esta tierra con más economía ${ }^{19}$.

18 Informe del Secretario de Estado del Despacho de Guerra de la Nueva Granada al Congreso Constitucional de 1852. Secretaría de Guerra, escrito por Valerio Barriga, Bogotá, 1852, BNC, Fondo Pineda: 33-40 y 28-29. Junguito, 2010: 113.

19 Informe del Secretario de Estado del Despacho de Guerra de la Nueva Granada al Congreso Constitucional de 1852. Secretaría de Guerra, escrito por Valerio Barriga, Bogotá, 1852, BNC, Fondo Pineda: 33-34. 
Hay que considerar la racionalidad y eficiencia de la burocracia estatal como significante de modernidad, sin embargo, muchos contratos no eran tan claros y transparentes, de forma que predominaban los intereses de un grupo de particulares generalmente comerciantes y especuladores con estratégicos contactos en las oficinas del Estado, que practicaban la corrupción: «una forma de influencia informal de los grupos de dominio económico» sobre los agentes públicos ${ }^{20}$. Sin embargo, antes de condenar estas prácticas, es necesario saber que se desarrollaban en el contexto de una incipiente economía de mercado, donde la inseguridad y la desconfianza hacía, como sucedía en la Hispanoamérica del siglo XIX, que las élites empresariales buscaran el amparo de políticos y funcionarios para reducir la incertidumbre, asegurar «negocios protegidos» y lograr del ente estatal las sustanciales demandas de artículos que no generaba el restringido mercado nacional. En consecuencia, se traficaban capitales, hombres, armas, mercancías, pasiones políticas y oscuros intereses, que se ensañaban en un Estado famélico y un fisco paupérrimo, mientras los negociantes «se lucraban con el descrédito del Estado». Todo ello expresa que definitivamente «la política era la clave de incontables nego$\operatorname{cios}^{21}$ » y que la corrupción podía ser un sustituto de la representación políti$\mathrm{ca}^{22}$.

Para que las acciones administrativas fueran efectivas dentro de una lógica centralizada, se requería de un tesoro y de sistemas contables, no sólo fuertes y efectivos, sino también «nacionales», según se los calificaba en el documento oficial; lo que significaba que los diferentes funcionarios de provincia debían adoptar procedimientos, trámites y documentos bajo formatos estandarizados, «completos, generales y uniformes» como se decía en el Informe citado anteriormente, de acuerdo con las leyes y reglamentos de tal dependencia. Como la centralización contribuye a la definición de ámbitos nacionales, se decidió que los gobernadores, por sus múltiples funciones en los diferentes ramos de la administración pública, no se encargaran más de los pagos y liquidaciones referidas a la Secretaría de Guerra. Para suplantarlos en el ejercicio de sus anteriores cometidos, el Gobierno de López determinó que se nombraran tres Comisarías de Guerra, localizadas en diferentes lugares del territorio nacional -Pasto, Cartagena y Panamá-, cuyos funcionarios actuarían como delegados del poder ejecutivo en tal ramo, encargados de ordenar y liquidar pagos de distinto orden con lógicas de «uniformidad», que supusieran procedimientos administrativos ho-

\footnotetext{
20 Escalante, 2009: 224.

21 Ibidem: 224, 256.

22 Bendix, 1966: 159, nota 64.
} 
mogéneos y la operatividad de una entidad administrativa unitaria e impositiva $^{23}$.

Considerar tales decisiones es de suma importancia, así como tener en cuenta las denominaciones, forma y léxico con que se denominaba lo que hoy consideramos como «Estado» y sus diversos organismos. Al respecto, la historiadora Annick Lempérere ha llamado la atención sobre la pertinencia de estudiar las representaciones del Estado, de modo que el punto de partida sea ponernos de acuerdo acerca de qué estamos hablando al evocar al Estado en Hispanoamérica ${ }^{24}$. En tal sentido y a pesar de la sinonimia que primaba en la época, entre Estado y Nación (como «cuerpos políticos» o «sociedades de hombres reunidos para procurar su salud y adelantamiento») se ha podido observar en muchos de los textos citados, en concordancia con tal autora, que eran muy comunes las referencias a los organismo estatales como «administración pública», «funcionarios públicos», «poder supremo», «poder central», «poder público» o el «poder ejecutivo», todas ellas «expresiones que se usaban con frecuencia abrumadora durante las décadas que siguieron el acceso a la independencia, sin excluir fórmulas de uso tradicional, como cargos públi$\cos$ o menos tradicional como empleados públicos» ${ }^{25}$.

Ilustrativo de la eficiencia administrativa en cuanto al control del orden público por parte del Estado en sus diversos niveles, es que una vez terminada la contienda se urgió la necesidad de controlar los persistentes focos de insubordinación y recoger las armas que estuvieran en poder de los «soldados y prosélitos de la rebelión», como lo ordenó el Jefe Político de la ciudad de Medellín, José María Faciolince: «Considerando que el caso que actualmente ocurre no es el de una simple retención de armas i otros útiles de guerra pertenecientes al Estado sin permiso de la autoridad; i por lo mismo, que no es este el caso [...] sino que es una ocultación deliberada i voluntaria i obstinadamente maliciosa de las armas e instrumentos con que se cometieron desde el 1 de julio los delitos de sedición, rebelión i trai-

23 Informe del Secretario de Estado del Despacho de Guerra de la Nueva Granada al Congreso Constitucional de 1852. Secretaría de Guerra, escrito por Valerio Barriga, Bogotá, 1852, BNC, Fondo Pineda: 45-46.

${ }^{24}$ Lempériére, 2007: 54-55.

25 Lempériére agrega: «Ahora bien, ¿qué sabemos de la significación que daban los actores a estas palabras clave del "Estado moderno"? Cuando dicen "administración pública", muchas veces cabe preguntarse si están hablando del "hecho de administrar las cosas públicas" (la justicia, el orden...), o si están pensando en un conjunto de concreto de oficinas y empleados dedicados a ejecutar leyes y las decisiones del gobierno. En la mayoría de los casos, y mientras no se lleve a cabo un estudio pormenorizado del asunto, el sentido es imposible de fijar con certeza», Ibidem: 55. Conde, 2009: 250-252. 
ción» ${ }^{26}$. Adicionalmente, en tal comunicación, el funcionario impartió instrucciones en las que reivindicó el respeto a la propiedad del Estado, al solicitar la devolución de bestias, bagajes y artefactos de guerra en poder de los particulares, lo que revela especial sensibilidad por la «cosa pública».

Como lo expresa este tipo de testimonios, tanto la centralización, como el monopolio de la violencia, son las dos caras de la moneda de lo que Norbert Elías denomina «mecanismo de monopolio», característico del Estado, y que significa una condición de civilidad como de modernidad para la vida política en común ${ }^{27}$. El control, entendido como institucionalización, se ajusta a la definición de una de las funciones estatales más destacadas por Charles Tilly, fundamental en la formación de los Estados en Occidente, en cuanto estos aparatos de poder han sido capaces de desplegar efectivos sistemas de administración y fuerza bajo los que se rige la comunidad nacional, lo que se ajusta al Estado como «el ente monopolizador de la violencia», según la clásica expresión de Max Weber ${ }^{28}$.

\section{Costos DE LA GUERRA Y PRECARIEDAD FINANCIERA DEL ESTADO}

Acorde con algunos estudios ${ }^{29}$, en la coyuntura de mediados del siglo XIX asociada a la Guerra Civil de 1851, se manifiesta la penuria económica del Estado debida a sus precarias condiciones fiscales y al desangre económico que significaban sus ingentes gastos ${ }^{30}$. Según críticos como el conservador y

${ }^{26}$ Carta de José María Faciolince desde Medellín al secretario encargado del Despacho de Guerra, 31 de octubre de 1851, Archivo General de la Nación (AGN), Sección República, Fondo Secretaría de Marina y Guerra, tomo 795, folios 600-603v. Comunicación dirigida al Jefe Político de la ciudad de Medellín el 24 de abril de 1852 por José María Faciolince, Archivo Histórico de Antioquia (AHA), Fondo Copiadores, tomo 1680, fol. 400r.

27 Elías, 5 (Medellín, 1998): 101-117. Anderson, 1982: 11.

28 «Con el crecimiento de las fuerzas armadas nacionales y el correlativo incremento de los presupuestos del Estado, casi todos ellos erigieron sistemas de control más amplios, mejor establecidos y más directos. El control central se extendió, obviamente, a la propiedad, la producción y la actividad política; los gobernantes dejaron de apoyarse en magnates altamente autónomos y presionaron hasta conseguir el mandato directo, hacia la creación de administraciones que se extendían directamente desde el poder central hasta las comunidades y los hogares». Tilly, 15 (Valencia, invierno de 1993): 82.

29 Véanse los trabajos de Malcolm Deas, Roberto Jungüito y Salomón Kalmanovitz, que forman parte de la sustanciosas compilación de Meisel y Ramírez, 2010. Igualmente Rojas, 67 (Medellín, julio-diciembre de 2007): 195-224.

30 Acerca de los costos de la guerra y el desorden de la administración militar ver Informe del Secretario de Estado del Despacho de Guerra de la Nueva Granada al Congreso Constitucional de 1851. Secretaría de Guerra, escrito por Valerio Barriga, Bogotá, 1851, BNC, 
líder rebelde Manuel Ibáñez, en ello influían las mismas Reformas Liberales, que dieron por resultado el recorte de rentas del Estado central provenientes de capitales a censos y la falta de créditos y recursos del Tesoro público y por la cesión de rentas centrales a las provincias como los estancos de aguardiente, diezmos, quintos, derechos de fundición, peajes provinciales y derechos y registros $^{31}$. Como consecuencia, se dio el cierre de colegios nacionales y establecimientos de beneficencia, lo que también afectó la administración del culto católico que se sustentaba con dichos emolumentos ${ }^{32}$. De igual forma argumentó, que las rentas municipales se encontraban en franco deterioro, puesto que la ley de Descentralización de Rentas (1850) las habían cargado de asfixiantes gastos que antes asumía la Administración nacional, por lo que se encontraban estancadas las inversiones en caminos, cárceles, cementerios, puentes y demás obras públicas locales. En igual sentido, el intelectual conservador José Manuel Restrepo afirmó de manera tendenciosa que tal ley no era más que el traslado del déficit de la nación a las provincias ${ }^{33}$.

La precariedad administrativa del Estado central a mediados del siglo XIX se comprende mejor si se sabe que al finalizar la contienda, la Secretaría de Guerra no podía ofrecer informes concluyentes sobre sus costos, y ello estaba muy relacionado con la fragmentación de los aparatos estatales de las provincias y la heterogeneidad de sus procedimientos administrativos ${ }^{34}$. En su informe al Congreso de la República, en marzo de 1852, el secretario de Guerra, Valerio F. Barriga, respondió al respecto: «Pidiéronse en circular de este

Fondo Pineda, pp. 3-23. Informe del Secretario de Estado del Despacho de Guerra de la Nueva Granada al Congreso Constitucional de 1852. Secretaría de Guerra, escrito por Valerio Barriga, Bogotá, 1852, BNC, Fondo Pineda. Restrepo, 1963: 145, 207, 214, 217 y 234-235.

31 Sólo se mantuvieron como rentas nacionales las aduanas, correos, amonedación, salinas, arrendamiento de baldíos, multas, arrendamientos, ingresos de capital y arrendamiento de vías nacionales. Junguito, 2010: 62.

32 Nuevas observaciones sobre la Administración del General José Hilario López en la Nueva Granada, escrito por Manuel Ibáñez, Lima, 24 de abril de 1853, AGN, Sección República, Fondo Folletería, pp. 25-26.

33 Restrepo, 1963: 141-142. A contrapelo de lo afirmado por Restrepo, en 1850 se habían cedido rentas de la nación a las provincias, estimadas en $\$ 500.000$ anuales, derivadas de aguardientes y diezmos. «Esto unido al establecimiento del impuesto único directo a nivel de las provincias, fortaleció sus fiscos. Con base en las cifras disponibles se puede estimar que entre 1851 y 1870 el aumento de las rentas de los estados fue de $165 \%$. Por su parte, el aumento de las rentas de la nación entre 1851 y 1870 fue de $118 \% »$; posteriormente se reversaron las tendencias. Junguito, 2010: 112.

34 El Estado puede ser considerado como «La organización constitucional y la jerarquía de las normas jurídicas, los poderes públicos y los aparatos administrativos que le permiten actuar en calidad de tales». Lempériére, 2007: 52. 
despacho [...] todas las noticias necesarias $\mathrm{i}$ al efecto, pero de mui pocas provincias se ha obtenido lo que se deseaba [...]» $\aleph^{35}$. De ahí que el conocimiento sobre los costos de la guerra provenga de cálculos aproximados de particulares o de algunos juiciosos funcionarios. Así las cosas, durante y después de la contienda, fue visible la imagen del Estado como aparato administrativo precario y débil en su fisco y en sus finanzas, en medio de una aporreada economía nacional, ya por la acuciante deuda extranjera e interna que venía de principios del siglo, la reducción de los impuestos y la falta de recursos en general. Esta situación fue vista de forma acertada por críticos opositores al Gobierno como José Manuel Restrepo, como el resultado de la nefasta gestión de los Gobiernos y los administradores de las oficinas estatales, los causantes de los desangres económicos agravados con las guerras y revoluciones. Este fue el sentido de su irónica intervención en marzo de 1852, frente a las desacertadas acciones del secretario Manuel Murillo Toro:

La posición rentística de la Nueva Granada era, pues, muy triste, y se aproximaba a una bancarrota. A pesar de esto Murillo nada proponía para aumentar los productos de las rentas públicas, y «su proyecto era vivir el porvenir cubriendo el déficit con el arbitrio de admitir las redenciones de censos, sobre el Tesoro, y contratando empréstitos ruinosos dentro y fuera del país». «Él decía que confiaba en los principios democráticos y en las mejoras que el tiempo y las riquezas de los ciudadanos introducirían en las rentas de la Nueva Granada», sin embargo, de que bajo la administración del 7 de marzo era un delito ser ricos y se les perseguía como agiotistas y monopolistas. Las esperanzas de Murillo eran verdaderas y tardías ilusiones, que podían no realizarse en un país tan expuesto a revoluciones como el granadino ${ }^{36}$.

Vale resaltar lo que han mostrado las investigaciones sobre la economía granadina durante el siglo XIX ${ }^{37}$, que ante las evidentes restricciones fiscales, los funcionarios estatales optaron por el crédito interno (deuda pública) para financiar el déficit fiscal, es decir, el desbalance entre ingresos y gastos, mecanismo que fue muy recurrido antes de 1880, cuando la emisión de dinero se implementó como alternativa al financiamiento fiscal. De allí que, según lo indicara Ángela Rojas, la deuda interna aumentara en coincidencia con las guerras civiles y por ello los gastos se ejecutaban contra los ingresos futuros, pues los corrientes habían sido pignorados por cuenta de la precedente con-

35 Informe del Secretario de Estado del Despacho de Guerra Valerio Barriga de la Nueva Granada al Congreso Constitucional de 1852. Secretaría de Guerra, escrito por Valerio Barriga, Bogotá, 1852, BNC, Fondo Pineda, p. 47.

36 Restrepo, 1963: 209-217. El entrecomillado es del autor.

37 Ver nota 29. 
tienda ${ }^{38}$. Se dimensiona mejor la gravedad de tal situación, si se sabe que antes de la guerra misma la Nueva Granada vivía una gravosa situación de estancamiento económico y de ello hacían parte las obligaciones de la deuda existente hacia 1850, cuyo servicio comprometía alrededor del 50\% de los ingresos corrientes nacionales asimilados a las exportaciones ${ }^{39}$. Así las cosas, la contienda venía a agravar la endeble situación fiscal ya existente, pero la misma situación fiscal expresaba condiciones de inestabilidad política ligadas, en parte, a los costos de la precedente, la Guerra de Los Supremos (1839-1842).

El liberal Salvador Camacho Roldán hizo un balance económico de la Guerra Civil de 1851, muy útil para tener una mirada global de la misma en materia financiera, debido a la precariedad de fuentes oficiales que permitan hacerlo. Planteó que la insurrección conservadora había quedado completamente vencida, y que aunque no tuvo una causa importante, «sí ocasionó una notable pérdida de vidas, un gasto inútil de más de dos millones de pesos al Tesoro nacional, desmoralización y rencores profundos». Indicó que una vez se inició la revuelta, el pie de fuerza nacional comenzó a elevarse, desde el mes de marzo de 1851 cuando se presentaron los primeros alzamientos en la provincia de Túquerres, y subió de manera sucesiva a los 10.000 hombres permitidos como máximo por la ley. Ésta fue una fuerza bastante considerable, pues el máximo para tiempos de paz estaba limitado a sólo $1.500^{40}$. En cuanto al gasto por soldado, Camacho Roldán lo estimó en no menos de un peso diario por cabeza, si se tiente en cuenta «[...] el pré del soldado, municiones, correaje, vestuario, traslación de sus diversos acantonamientos, marchas, hospitales, etc. [...] sobre todo teniendo en cuenta que en esas épocas de desor-

38 Rojas, 67 (Medellín, julio-diciembre de 2007): 199. El mecanismo es perverso «(..) cuando los gobiernos se endeudan sistemáticamente sin preocuparse por el pago futuro y aumentan sus obligaciones contratando nuevos préstamos para cancelar el servicio de los existentes. El examen detallado de los balances de crédito público y las Memorias de Hacienda y del Tesoro revela que éste último fue el caso de Colombia. Por supuesto, la frecuencia de las guerras civiles (...) explica este comportamiento»; Rojas, 67, (Medellín, julio-diciembre de 2007): 200.

39 Ibidem, 202.

40 Camacho, 1946: 89-90. Informe del Secretario de Estado del Despacho de Guerra de la Nueva Granada al Congreso Constitucional de 1851. Secretaría de Guerra, Bogotá, escrito por Valerio Barriga, 1851, BNC, Fondo Pineda, p. 2. Informe del Secretario de Estado del Despacho de Guerra de la Nueva Granada al Congreso Constitucional de 1852. Secretaría de Guerra, escrito por Valerio Barriga, Bogotá, 1852, BNC, Fondo Pineda, pp. 3, 4, 30-31. Desde junio de 1850 se buscó elevar el pie de fuerza, según el «Cuadro del contingente de hombres con que deben contribuir las provincias de la República en el próximo año económico [se refiere a 1851]», bajo la Ley de 1 de julio de 1850, AGN, Gaceta Oficia. n. ${ }^{\circ} 1137$, 14 de julio de 1850, p. 339. 
den sube de proporción el número de jefes y oficiales» ${ }^{41}$. En definitiva, estimaba el costo total de la contienda en una suma de $\$ 2.000 .000$ de pesos, si se consideran los $\$ 10.000$ diarios para un período de seis meses ${ }^{42}$. Si se relacionan estas cifras con las aportadas por Roberto Junguito, se tiene que los costos de la guerra fueron equivalentes al gasto público anual a cargo de la nación durante la década de los años de 1850, que era de alrededor de \$ 2.000.000 de pesos, lo que significaba un ingente esfuerzo financiero para un Estado enclenque ${ }^{43}$.

Así las cosas, era claro que inevitablemente la guerra afectaba la composición del gasto público, con la finalidad de ampliar la capacidad del Estado para la financiación de todo lo relativo al ejército y otras fuerzas armadas dirigidas desde la Secretaría de Estado del Despacho de Guerra y Marina ${ }^{44}$. En este sentido, indagaciones sobre el tema apuntan en la misma dirección que se ha expuesto acá, y es que la deuda interna a cargo del Estado:

(...) reflejó los costos de las guerras civiles y el déficit operacional de la administración pública. Estos costos comprendían suministro de particulares a los ejércitos (ganado, armas, municiones, bienes raíces, etc.), empréstitos voluntarios y contribuciones forzosas. El déficit primario incluía obligaciones de Tesorería por cubrir, como salarios, pensiones, pagos por servicios administrativos, contratos y adjudicaciones, así como los intereses generados por la misma deuda interna. Gran parte de esta deuda fueron compromisos de carácter compulsivo y ex post y sólo una parte pequeña, (un porcentaje bajo de la deuda flotante), constituyó un verdadero endeudamiento, en cuyo caso, quienes proporcionaban dinero al gobierno lo hacían libremente exigiendo una alta tasa de interés que compensara el riesgo de la operación y una recuperación casi inmediata de los fondos cedidos ${ }^{45}$.

Es importante estimar las dimensiones económicas de esta institución, pues los costos aumentaban y los ingresos disminuían en tiempos de guerra,

41 AGN, Sección República, Fondo Secretaría de Guerra y Marina, tomo 799, folios 107, 122-124.

$42 \mathrm{Al}$ respeto dice Roberto Junguito: «Uno de los resultados más interesantes que se desprenden de este trabajo es la incidencia que tuvieron las guerras civiles en las finanzas públicas y, particularmente, en el monto y composición del gasto público. Es claro que los gastos militares, incluyendo remuneraciones al ejército y armamentos y provisiones, fueron los principales responsables de las necesidades de endeudamiento externo luego de la Independencia». Junguito, 2010: 115-116.

43 Ibidem: 113.

44 Gasto que para los años de 1842-1843, que cubría la Guerra de Los Supremos, ascendió al 60\% del total y una vez terminada, descendió al 38\%. Junguito, 2010: 116.

45 Rojas, 67, (Medellín, julio-diciembre de 2007): 203-204. Vale la pena aclarar que la «deuda flotante» era aquella definida por los pagos más urgentes a corto plazo, mientras que la «consolidada» implicaba obligaciones y pagos de capital a largo plazo. 
gastos que era incapaz de solventar el Estado por su excesivo peso dentro del gasto público nacional, de modo que al decir de Frank Safford, entre 1832 y 1845 la organización castrense absorbió cerca de la mitad del presupuesto nacional, mientras que después de 1845 este rubro descendió a un cuarto y a finales de la década de 1850 , al 12\%, como resultado de la disminución efectuada por el Radicalismo sobre el ejército nacional dentro de su concepción del «Estado mínimo» ${ }^{46}$.

Lo expuesto hasta ahora muestra la importante centralidad de lo financiero para la organización y estabilidad estatal y la racionalización como elemento de administración pública. Al respecto, vale la pena recordar la expresión de Jünger Habermas, al indicar que «El Estado es la administración pública». «El Estado moderno es esencialmente Estado impositivo, y la administración financiera la pieza clave de su administración general» ${ }^{47}$.

La guerra como un grave problema financiero para el Estado no fue incompatible con la representación de ser un evento político que comprometía el destino deseable para la nación como de «progreso», de modo que fue significada por algunos de sus actores como una más de las revoluciones que obstaculizaron el camino de la nación a la «civilización», pero al mismo tiempo el atraso económico aparecía, no como su consecuencia, sino como su causa $^{48}$. Asumida como un drama de la vida política nacional, la guerra participaba de las representaciones de una comunidad imaginada con una tragedia compartida y un devenir político tormentoso y accidentado por la persistencia de los conflictos y las revoluciones civiles, asociada a la incipiente modernidad de la época, vista como atraso (falta de «civilización»), denominado hoy como «subdesarrollo».

\section{ACCIONES POLÍTICAS Y PRECARIEDAD ESTATAL}

Tras varios intentos de asonadas en localidades del Sur-occidente al iniciar el Gobierno de López, éste dictó una directriz para controlar el orden interno: hacer oficial la organización de la Guardia Nacional Auxiliar como fuerza

46 Safford, 1989: 70. López, 14 (Medellín, 1999): 83-86.

47 Habermas, 2009: 24, 56.

48 Un amante de la paz, «C. General Tomás Herrera», Medellín, 20 de septiembre de 1851, Medellín, Imprenta de Jacobo F. Lince, 1851, disponible en Biblioteca Central Universidad de Antioquia, Sala de Patrimonio, Fondo Hojas Sueltas. Nuevas observaciones sobre la Administración del General José Hilario López en la Nueva Granada, escrito por Manuel Ibáñez, Lima, 24 de abril de 1853, AGN, Sección República, Fondo Folletería, pp. 25-26. Restrepo, 1963: 209-217. 
armada para enfrentar a los posibles rebeldes ${ }^{49}$. Esta política, que ya había sido implementada espontáneamente en las localidades, muestra la forma en que el Estado se hacía presente en los ámbitos locales como una fuerza de acción militar centralizada, única y unificada ${ }^{50}$. Benedict Anderson ha destacado la importancia que han jugado estos elementos en el largo proceso de la construcción de las naciones europeas y americanas en tanto creación de aparatos de poder controlados por los gobernantes; la unificación, por ejemplo, ha significado «el intercambio interno de hombres y documentos» y el reclutamiento de hombres para tropas y ejércitos ${ }^{51}$. Sin embargo, como se ha expuesto, las acciones militares y administrativas del Estado neogranadino desde sus diversas dependencias se llevaron a cabo en un contexto de extrema precariedad financiera, de un incipiente profesionalismo militar y burocrático, y de una secular falta de recursos técnicos en medio de una fragmentada y difícil geografía, debido a la falta de caminos y medios de comunicación efectivos para penetrar su vasto territorio.

Si bien los cuerpos armados de los conservadores podían ser tan precarios o más que los del Estado, asimilables a montoneras y guerrillas faltas de recursos, aquel en realidad no contaba con un cuerpo armado bien dotado, según se colige de testimonios documentales, sobre todo para las alejadas zonas de frontera. Allí se revelan aspectos de la penosa situación de las fuerzas al mando del general José María Obando en el Sur, cuando se presentó el desacuerdo entre él y el general Manuel María Franco, por la invasión al Ecuador que preparaba éste último, pues «no teníamos más que treinta i siete mil cartuchos $[\ldots]$ no podíamos recibir municiones en pequeño número antes de un mes $[\ldots]$ sin dinero para racionar la tropa». Además no tenían un «cuerpo de reserva», ni «una línea de operaciones» para replegarse en caso de ser necesario, con el gran riesgo de que, en una zona de guerrillas, quedasen aislados del Gobierno central al pasar la frontera, «sin esperanzas de recibir

49 Comunicación de la Parroquia de La Sierra al gobernador de la provincia de Popayán, el 14 de septiembre de 1851, Archivo Central del Cauca (ACC), Archivo Muerto, Fondo Correspondencia Militar, sin tomo, sin folio. Comunicación del alcalde de Silvia al gobernador de la provincia de Popayán, el 17 de julio de 1851, ACC, Fondo Correos Gobierno, sin tomo, sin folio. Comunicación del jefe político del cantón de Popayán, Andrés Cerón, al gobernador de la provincia de Popayán, el 31 de julio de 1851, ACC, Fondo Asuntos Militares, tomo 1851, paquete 50, archivo 50, sin folio.

50 Comunicación del secretario José María Plata a los gobernadores de las provincias de la Nueva Granada, Bogotá, 22 de julio de 1851, ACC, Fondo Correos Gobierno, tomo 1852, sin folio. Arboleda, 1990: 249-250.

51 Anderson, 2003: 87-88. 
ausilio alguno ni quedarnos en un punto de apoyo; pero ni de asilo en caso de un revés» $\rangle^{52}$.

En este sentido, el esfuerzo estatal por enfrentar la competencia de poder que le suponían los rebeldes fue, muchas veces, un esfuerzo por no perder la poca organicidad e integralidad administrativa que se había logrado en tres décadas de vida republicana. Para mostrar la complejidad de las acciones del Estado y la forma en que ponían al desnudo su precariedad y debilidad, se pueden citar aspectos de la desgastada guerra que se libró en la vasta y alejada zona de frontera del sur-occidente de la República, cerca del Ecuador, en el intento de sofocar las guerrillas de la zona, hasta marzo de $1852^{53}$. La forma en que se sostuvieron las tropas del Gobierno ofrece serios indicios sobre su pobreza y debilidad, según lo muestra la correspondencia entre las autoridades civiles y militares. Desde las más recónditas localidades en la frontera con Ecuador se solicitaba con desesperación a las autoridades liberales de Bogotá o de las ciudades más cercanas como Pasto, Popayán o Cali municiones y todo tipo de avituallamiento, que siempre llegaba con retraso, cuando llegaba ${ }^{54}$.

Entre las tropas asentadas en Pasto, donde se encontraban los generales Obando y Franco, existía el cargo de Comisario Pagador con la finalidad de administrar el dinero de la Administración de Correos, desde donde se pagaba diariamente la ración de la tropa, sin embargo, muchas veces hubo déficit y los altos mandos militares y ciudadanos prominentes debieron recurrir a su propio peculio para dotarla de lo necesario: «para ello el mismo general Obando, algunos jefes y varios ciudadanos, empeñaron su crédito personal i consiguieron recursos para satisfacer las necesidades del soldado ${ }^{55}$.

Como era bastante difícil que los ejércitos oficiales se sostuvieran con los dineros y recursos provistos por el Estado central, los combatientes recurrieron con frecuencia a las confiscaciones efectuadas en el campo de batalla y a los empréstitos forzosos. Fue así como Obando y las autoridades locales dispusieron de las encomiendas de barras y onzas de oro confiscadas a las tropas del rebelde Manuel Ibáñez en Pasto, provenientes de la Administración

52 Contestación al folleto del General Franco titulado »A la nación y al gobierno», por Fénix, Popayán 26 de junio de 1852, ACC, Fondo Fuentes Impresas, p. 6.

53 AGN, Sección República, Fondo Secretaría de Marina y Guerra, tomo 995, folios 540552; tomo 799, folios 113-113v y 609-613. Comunicación del general José María Obando al gobernador de Popayán el 17 de julio de 1851, ACC, Fondo Correos Gobierno, paquete 50, archivo 50, sin folio.

54 ACC, Fondo Correos Gobierno, tomo 1851, paquete 50, archivo 50.

55 Contestación al folleto del General Franco titulado «A la nación y al gobierno», por Fénix, Popayán 26 de junio de 1852, ACC, Fondo Fuentes Impresas, pp. 2-3. 
de Correos, que se cargaron a los gastos de la Gobernación de Barbacoas. La suma ascendió a $\$ 6.000$ pesos y «fue invertida en raciones i en otros suministros indispensables al soldado que de todo carecía». Las tropas también fueron dotadas con las 350 bestias que se tomaron en Pasto y Túquerres a varios particulares. Según versión de sus hombres, Obando fletó caballerías en Pasto para sus propias tropas «pagadas de su propio peculio porque no se le dio ausilio alguno para su marcha i no faltó oficial que viniese de a pie» ${ }^{56}$. Éste, como otros tantos testimonios, nos recuerda que la relación de los caudillos decimonónicos respecto de los ejércitos, tenía un sentido patrimonialista, como si se tratara de un importante «recurso político» personal, facilitado por la escasez de medios del órgano estatal y la fragmentación geográfica: «Los jefes manejaban las tropas como ejércitos patrimoniales, de los cuales solían disponer al margen de las instituciones jurídicas y de las autoridades civiles ${ }^{57}$.

Las localistas y aisladas iniciativas de Obando al respecto son tanto más importantes por cuanto las comunicaciones con Bogotá y la misma ciudad de Popayán fueron demasiado lentas, cuando las hubo, de manera que la correspondencia referente a este asunto es una verdadera muestra del desengaño y la desilusión de este militar, frente a la supuesta desidia del Gobierno, que prácticamente lo dejó abandonado y casi aislado en la frontera Sur. De ahí que fuera célebre el atentado que sufriera a manos de las ultramontanas guerrillas de la zona y que la penosa situación de Obando expresara las serias limitaciones del Estado para desplegar su efectiva coacción en un lejano territorio. El problema de las guerrillas de Pasto pone de manifiesto la «crisis de penetración» del Estado del siglo XIX, debido a su incapacidad para cubrir y desplegar su presencia a todo lo largo de la nación, en la medida en que ello significaba el desarrollo de una burocracia racional para movilizar recursos fiscales, de justicia y acción administrativa y militar, con la finalidad de controlar el orden público y coordinar tareas colectivas ${ }^{58}$.

Una vez terminada oficialmente la guerra, en septiembre de 1851, la División del Sur, a cargo de Obando, permaneció en Pasto y protegió a Túquerres necesitada de urgentes armas y recursos para mantener sus hambrientas

56 Contestación al folleto del General Franco titulado «A la nación y al gobierno», por Fénix, Popayán 26 de junio de 1852, ACC, Fondo Fuentes Impresas, p. 3.

57 La dotación y disposición personalista de los ejércitos por parte de los caudillos mexicanos decimonónicos, hace recordar que los ejércitos eran, antes que otra cosa, un importante »recurso político» y la escasez de medios lo facilitaba. Escalante, 2009: 166. Contestación al folleto del General Franco titulado »A la nación y al gobierno», por Fénix, Popayán 26 de junio de 1852, ACC, Fondo Fuentes Impresas, p. 3.

58 Orozco, 2006: 99 y 104. 
y mal dotadas tropas. En la idea de que ya habían sido derrotadas los rebeldes del interior del país y que los ejércitos liberales en las demás provincias tenían un respiro por el triunfo sobre los conservadores (el 10 de septiembre) y que fuera posible desplazar hombres hacia el Sur, Obando solicitó permanentemente al Gobernador de Popayán reclutas de las ciudades de Bogotá y de Buga con el fin de remplazar los agotados hombres de la Guardia Nacional bajo su mando ${ }^{59}$. Hacia el 14 de octubre, las demandas de Obando se tornaron en desilusionadas súplicas e indignación debido a la indolencia de las autoridades liberales para responder a sus pedidos de dotarlo de nuevas tropas que no estuvieran agotadas y en deplorable estado de pobreza:

Ya se me ha agotado el diccionario de las súplicas y de los ruegos y no me queda más que el de la indignación por la indolencia invencible con que hasta ahora se ha mirado los sucesos de esta provincia. [...] Los frecuentes tiroteos que ha habido que sostener se han terminado por conclusión de municiones, y aunque desde junio he clamado incesantemente hasta ahora por este elemento primero de la guerra, no he recibido lo que tantas veces me han anunciado que iba a salir. [...] Ya me duele el corazón y la lengua señor Gobernador de tanto pedir y suplicar; y mil veces me arrepiento de haber aceptado el destino que me ha encargado el Gobierno en el cual tiempo más fatigas y más trabajo por la indolencia de los agentes del P. E. que lo mucho que hubiera que hacer contra los rebeldes ${ }^{60}$.

Las acciones guerrilleras en la región pastusa se prolongaron por casi un año y sólo hacia marzo de 1852 se consideraron derrotadas. Ello demuestra la complejidad que revestía la presencia del Estado para actuar como un efectivo organismo de coacción que garantizara el orden público en una zona tan montañosa y de frontera, donde, además, la acción estatal estuvo sometida a las veleidades y pugnas entre los generales Obando y Franco ${ }^{61}$. De igual modo, la prolongación de las acciones contra las guerrillas del Sur, cuando ya se había decretado oficialmente terminada y ganada la guerra, manifiesta que definitivamente el mantenimiento del orden no era uniforme en todo el territorio. Con todo, la prolongación del conflicto en el Sur y las persistentes amenazas de reactivación de las rebeliones en distintas regiones y localidades

59 Comunicación del general José María Obando al gobernador de Popayán, desde Pasto el 15 de agosto de 1851, ACC, Fondo Correos Gobierno, paquete 50, archivo 50, sin folio. Se trataba de una medida urgente para «salvar la patria en la frontera», debido a la ruina, agotamiento y pésima dotación de su División. ACC, Sala República, paquete 50, pieza 50, año de 1851. También: Andrade, 1982: 163.

60 ACC, Sala República, paquete 50, pieza 50, año de 1851.

${ }^{61}$ Lo expuesto en este apartado desmiente la afirmación de Alonso Valencia Llano, en el sentido de que, en la etapa final del conflicto el General Obando, a diferencia del General Herrera, no jugó un papel tan importante. Valencia, 2008: 203. 
generaron tal clima de incertidumbre que todo ello podría sintetizarse en la fórmula del político y publicista estadounidense del siglo XVIII, Thomas Paine, en términos de que: «un gobierno que no puede preservar la paz, no es un gobierno» ${ }^{62}$.

Para comprender las complejidades de la política nacional, y del despliegue del Estado en el Sur, es necesario saber que allí las estrategias militares no estuvieron unificadas a causa de las serias discrepancias entre Obando y Franco. Éste último se sintió apabullado por la exagerada simpatía de los sectores populares del Sur hacia Obando y por su innegable experiencia y pragmatismo en el campo de batalla, mientras que él se mostraba más formal, apegado a las normativas legales y a los procedimientos burocráticos impuestos desde la lejana Bogotá. Acá se hicieron evidentes las diferencias de dos recias personalidades, acrecentadas por su mayor autonomía para decidir el curso de la guerra lejos de los entes gubernamentales, una muestra de la compleja trama entre lo nacional y lo local, y una manifestación del carácter carismático y clientelar con que se manejaban los ejércitos. Fue tan evidente la gran ascendencia de Obando sobre las tropas, conformadas en gran parte por pobladores del Cauca, y tan intolerante para Franco y sus hombres, que éstos acuñaron la expresión de que existía un «partido obandista» entre la soldadesca. Esto es más comprensible si se tiene en cuenta que Obando, además de militar, fue un avezado caudillo, político y negociador con amplia experiencia e influencia, tanto en la región como a escala nacional, mientras que Franco gozaba de menos popularidad entre la tropa y era más inclinado a que «todo se hiciese a punta de lanza». Así lo deja entrever el testimonio de uno de los hombres de Obando sobre su proceder para enfrentar las guerrillas que arreciaban sobre Pasto, pues aprovechó su influjo y posición y «empleó otros medios que ya le eran conocidos i consiguió que el clérigo Santacruz [líder de las guerrillas] se presentara»: "se le indultó i con él desapareció una guerrilla de más de cien hombres que nos amenazaba hostilmente». El rebelde entregó más de 50 fusiles «i a su vos» los habitantes de La Florida y la mayor parte de los del Tambo se separaron de la facción. Muchos de los comprometidos solicitaron indulto, sobre todo «las personas de influjo y valer, quedando las guerrillas capitaneadas por hombres insignificantes i obstinados $»^{63}$.

62 Citado por Escalante, 2009: 128.

63 Contestación al folleto del General Franco titulado "A la nación y al gobierno», por Fénix, Popayán 26 de junio de 1852, ACC, Fondo Fuentes Impresas, p. 5. Como lo dice el título del folleto firmado bajo el seudónimo de «Fénix», se trataba de una »contestación»a otro del General Franco, donde éste elevó acusaciones contra Obando sobre su proceder y el manejo de los recursos económicos y en especie en la zona. 
La documentación analizada ofrece indicios de que Obando pudiera inclinarse por el tratamiento de la guerra y de sus enemigos guerrilleros desde un modelo político-militar que privilegiaba la negociación y la simetría con los opositores, a quienes se considera contrincantes pero en el fondo socios inter-pares, merecedores de ser reconocidos con un estatus privilegiado cercano al del beligerante, y por ello sujetos de negociación y de re-inserción en la sociedad; de allí que desde este modelo, se valore la paz sobre la aplicación de la justicia y el castigo, lo que supone la aplicación de lenidad estatal con indultos y amnistías que permiten el «borrón y cuenta nueva». Franco, por su parte, parecía representar el modelo opuesto, policivo-punitivo de confrontación asimétrica con el combatiente rebelde, que por su condición de delincuente o guerrilleros y su práctica de la guerra irregular, mal vista por las elites militares criollas, fueron asociados con la ilegalidad, lo que los hacía merecedores de su criminalización y no de consideraciones como delincuentes políticos ${ }^{64}$.

De igual forma, los testimonios documentales evidencian que la guerra fue un espacio propicio para la cristalización de líderes y políticos de talla nacional como Obando, por su fama y gran popularidad de caudillo, y que el Estado no era un ente preexistente que desplegaba su accionar funcionalmente, sino que él mismo se construía en el campo de fuerzas sociales y políticas que hacían posible y urgente su despliegue. De manera que los asuntos de soberanía estatal y administración pública no eran nada abstractos, sino que por el contrario, la institucionalidad estatal se definía en el campo de las contingencias, los afanes de la guerra y las tramas del poder político y del carisma personal de sus militares y funcionarios. El análisis de la variada documentación archivística indica que a pesar de la flaqueza de los cuerpos burocráticos del Estado en cuanto a medios, profesionalismo de sus funcionarios y mecanismos administrativos para hacer efectivo el monopolio de la violencia, el Estado neogranadino no dejó de ser el referente institucional para los rebeldes conservadores. Como lo indica Ernest Gellner, hay Estados que a pesar de su debilidad no dejaron de ser, en muchos aspectos, «Estados reconocibles» ${ }^{65}$.

\section{Consideraciones finales}

Luego de todo lo expuesto, puede decirse que en el corto plazo, la Guerra Civil de 1851 afectó las condiciones del desarrollo nacional, en cuanto signi-

64 Acerca del análisis de ambos modelos: Orozco, 2006: XXI-XXVII, 111.

65 Gellner, 2003: 16. 
ficó un evento más del deterioro financiero del Estado central, mientras que debido a su corta duración y su localización en algunas regiones, sus efectos en la economía y las actividades productivas pudo ser ínfimo en comparación con los generalizados y nefastos efectos de las clásicas guerras del siglo XIX, la de 1860 y la de Los Mil Días (1899-1902). En este sentido la guerra implicó un deterioro del gasto público del Estado dirigido al sostenimiento de las tropas y ejércitos, rublo que llegó a pesar entre la mitad y un cuarto del presupuesto nacional, lo que agravó la crisis fiscal que ya era preocupante desde la época de la Independencia, el aumento de la deuda interna y puso de manifiesto la debilidad política del Estado por su falta de recursos financieros y de disposiciones administrativas unificadas.

Aunque la Guerra Civil de 1851 fue muy breve como para permitir una gran expansión administrativa y burocrática del Estado, en medio del esfuerzo bélico que ella demandaba, puso de manifiesto que algunos de sus órganos como la Secretaría de Guerra y Despachos del Ejecutivo, ampliaron su accionar e hicieron posible la presencia del ente central a lo largo del territorio nacional con una amplia variedad de funciones de administración de los recursos públicos. Es necesario reconocer que la precariedad del aparato administrativo del Estado durante el siglo XIX fue evidente, y de ahí la importancia que tuvieron las guerras civiles; a corto plazo, ocasionaron un franco deterioro de los recursos del Estado neogranadino y de su capacidad impositiva y de penetración del territorio y su población, pero, a largo plazo, podían suscitar aprendizajes de administración pública que obligaron, por fuerza de las circunstancias, a consolidar su acción política y a ser el principal referente de la función gubernativa y de representación de la comunidad nacional por su papel en la gestión y administración de la Res-pública.

El análisis de la variada documentación archivística indica que a pesar de la flaqueza de los cuerpos burocráticos del Estado en cuanto a medios, profesionalismo de sus funcionarios y mecanismos administrativos para hacer efectivo el monopolio de la violencia, el Estado no dejó de ser el referente institucional para los rebeldes conservadores. Como lo indican algunos teóricos, hay Estados que a pesar de su debilidad no dejan de ser, en muchos aspectos, «reconocibles». En este sentido, el Ejecutivo (con sus generales) fungió como interlocutor político de los rebeldes y como órgano administrativo centralizado y coactivo, ajustándose al «mecanismo de monopolio», elemento de modernidad que tuvo lugar en medio de su precariedad, la falta de recursos financieros, la férrea resistencia de las guerrillas del Sur y de la Iglesia, y las dificultades para hacer presencia en un lejano territorio de fronteras con el Ecuador. De manera que los asuntos de soberanía estatal y administración pública no eran nada abstractos, sino que por el contrario se debatieron en el 
campo de las contingencias y las tramas del poder de personas de carne y hueso que hicieron tangible la presencia de tal institución por medio de funcionarios, políticos y militares.

\section{BiBLIOGRAFÍA}

Anderson, Benedict, Comunidades imaginadas. Reflexiones sobre el origen y la difusión del nacionalismo, México, Fondo de Cultura Económica, 2003.

Anderson, Perry, El estado absolutista, México, Siglo XXI Editores, 1982.

Andrade González, Gerardo, José María Obando. Obras Selectas. Escritos civiles y militares, Bogotá, Imprenta Nacional, 1982.

Arboleda, Gustavo, Historia contemporánea de Colombia, tomos III, V y VI, Bogotá, Banco Central Hipotecario, 1990.

Bendix, Reinhard, Trabajo y autoridad en la industria. Las ideologías de la dirección en el curso de la industrialización, Buenos Aires, EUDEBA, 1966.

Camacho, Salvador, Memorias, 2 tom., Bogotá, ABC/Biblioteca Popular de Cultura Colombiana, 1946.

Conde Calderón, Jorge, Buscando la nación. Ciudadanía, clase, y tensión racial en el Caribe colombiano. 1821-1855, Medellín, La Carreta Editores, 2009.

Deas, Malcolm, "La presencia de la política nacional en la vida provinciana, pueblerina y rural del Colombia en el siglo XIX de la república", Marco Palacios, et al. (eds.), La unidad nacional en América Latina: del regionalismo a la nacionalidad, México, El Colegio de México, 1983: 149-173.

Elias Norbert, "Los procesos de formación del Estado y de construcción de la nación", Historia y Sociedad, 5 (Medellín, 1998): 101-117.

Escalante Gonzalbo, Fernando, Ciudadanos imaginarios, México, El Colegio de México, 2009.

Gellner, Ernest, Naciones y nacionalismo, Madrid, Alianza Editorial, 2003.

González, Fernán, Poderes enfrentados. Iglesia y Estado en Colombia, Santafé de Bogotá, CINEP, 1997.

Habermas, Jünger, Historia y crítica de la opinión pública. La transformación estructural de la vida pública, Barcelona, Gustavo Gili, 2009.

Helguera J. León, "Antecedentes sociales a la revolución de 1851 en el sur de Colombia (1848-1849)", Anuario de Historia Social y de la Cultura, 5 (Bogotá, 1970): 53-63.

Hobsbawn Eric, Naciones y nacionalismo desde 1870, Barcelona, Crítica, 2000. 
Junguito, Roberto, "Las finanzas públicas en el siglo XIX”, Adolfo Meisel y María Teresa Ramírez (eds.), Economía colombiana del siglo XIX, Bogotá, Fondo de Cultura Económica y Banco de la República, 2010: 41-134.

Jurado Jurado, Juan Carlos, "Reclutas, pobres y soldados en las guerras civiles colombianas", Revista de Indias, LXIV/232 (Madrid, 2004): 673-696.

Jurado Jurado, Juan Carlos, "Reinventar la nación a partir de la fe católica. De la religión el clero y la política en la Guerra civil de 1851”, Historia y Sociedad, 15, (Medellín, julio-diciembre 2008): 43-88.

Jurado Jurado, Juan Carlos, "La división de la provincia de Antioquia en medio de la Guerra Civil de 1851”, Historia y Sociedad, 17 (Medellín, julio-diciembre de 2009): 121-158.

Jurado Jurado, Juan Carlos, "La participación del pueblo liberal en la Guerra Civil de 1851: la ciudadanía en armas”, Análisis Político, 71 (Bogotá, abril 2011): 3-28.

Lempériére Annick, "La historiografía del Estado en Hispanoamérica. Algunas reflexiones", Guillermo Palacios (coord.), Ensayos sobre la nueva historia política de América Latina, S. XIX, México, El Colegio de México, 2007: 45-62.

López Liliana, "La ciudadanía miscelánea del liberalismo radical en Colombia”, Estudios Políticos, 14 (Medellín, 1999): 74-104.

Meisel Roca, Adolfo y Ramírez, María Teresa (eds.), Economía colombiana del siglo XIX, Bogotá, Fondo de Cultura Económica y Banco de la República, 2010.

Orozco Abad, Iván, Sobre los límites de la conciencia humanitaria, Bogotá, Editorial Temis/Universidad de los Andes, 2005.

Orozco Abad, Iván, Combatientes, rebeldes y terroristas. Guerras y derecho en Colombia, Bogotá, Editorial Temis, 2006.

Ortiz Mesa, Luis Javier, El Federalismo en Antioquia. Aspectos políticos, 1850-1880, Bogotá, Editorial Gente Nueva/Universidad Nacional de Colombia, Sede Medellín, 1985.

Palacios, Marco, Parábola del liberalismo, Bogotá, Editorial Norma, 1999.

Rojas, Ángela Milena, "Deuda pública interna, patrón metálico y guerras civiles: interconexiones institucionales, la Colombia del siglo XIX”, Lecturas de Economía, 67 (Medellín, julio-diciembre de 2007): 195-224.

Restrepo, José Manuel, Diario político y militar. Memorias sobre los sucesos importantes de la época para servir a la historia de la revolución de Colombia y de la Nueva Granada, desde 1835 para adelante, 4 tomos, Bogotá, Imprenta Nacional, 1954.

Restrepo, José Manuel, Historia de la Nueva Granada, tomo II, Bogotá, Editorial El Catolicismo, 1963. 
Safford, Frank, El ideal de lo práctico: el desafío de formar una elite técnica y empresarial en Colombia, Bogotá, Universidad Nacional de Colombia / El Áncora Editores, 1989.

Skocpol, Theda, Los estados y las revoluciones sociales, México, Fondo de Cultura Económica, 1983.

Tilly, Charles, Coerción, capital y estados europeos, 990-1990, Madrid, Alianza Editorial, 1992.

Tilly, Charles, "Cambio social y revolución en Europa. 1492-1992", Historia Social, 15 (Valencia, invierno 1993): 71-98.

Uribe de Hincapié, María Teresa, "Las guerras por la nación en Colombia durante el siglo XIX", Estudios Políticos, 18 (Medellín, enero-junio de 2001): 9-27.

Uribe de Hincapié, María Teresa y López, Liliana, Las palabras de la guerra. Un estudio sobre las memorias de las guerras civiles en Colombia, Medellín, La Carreta/ Instituto de Estudios Políticos de la Universidad de Antioquia y Corporación REGIÓN, 2006.

Valencia Llano, Alonso, "La guerra de 1851 en el Cauca", Memoria de la II Cátedra Anual de Historia "Ernesto Restrepo Tirado». Las guerras desde 1830 y su proyección en el siglo XX, Bogotá, Museo Nacional de Colombia, 1998.

Valencia Llano, Alonso, Dentro de la ley. Fuera de la ley. Resistencias sociales y políticas en el Valle del Cauca. 1830-1855, Cali, Centro de Estudios Regionales Región y Universidad del Valle, 2008.

Fecha de recepción: 1 de enero de 2012.

Fecha de aceptación: 15 de diciembre de 2012.

\section{War as government administration. The Colombian Civil War of 1851}

War is chaos and destruction but it has led to the construction of modern orders such as the nation-state. In this article, the Colombian Civil War (1851) is studied as an administrative experience for the State, because it required the planning, coordination and control of huge resources in order to govern and build up its political legitimacy. Political actions seen as administrative actions, war costs, and the instability of the State are all examined in the light of the analysis of memoires, chronicles, official reports and the periodical press.

KEY WORDS: 1851 civil war; administration; nation construction. 